\title{
Eon de Beaumont, La Pucelle de Tonnerre: les Vicissitudes du Chevalier et de la Chevalière d'Eon
}

\section{Maria Immacolata Spagna}

\section{(2) OpenEdition}

1 Journals

\section{Edizione digitale}

URL: https://journals.openedition.org/studifrancesi/40812

DOI: $10.4000 /$ studifrancesi.40812

ISSN: 2421-5856

\section{Editore}

Rosenberg \& Sellier

\section{Edizione cartacea}

Data di pubblicazione: 1 juillet 2004

Paginazione: 201-202

ISSN: 0039-2944

\section{Notizia bibliografica digitale}

Maria Immacolata Spagna, «Eon de Beaumont, La Pucelle de Tonnerre: les Vicissitudes du Chevalier et de la Chevalière d'Eon», Studi Francesi [Online], 142 (XLVIII | I) | 2004, online dal 30 novembre 2015, consultato il 09 septembre 2021. URL: http://journals.openedition.org/studifrancesi/40812 ; DOI: https://doi.org/10.4000/studifrancesi.40812

Questo documento è stato generato automaticamente il 9 septembre 2021.

\section{(c) $(1) \ominus$}

Studi Francesi è distribuita con Licenza Creative Commons Attribuzione - Non commerciale - Non opere derivate 4.0 Internazionale. 


\title{
Eon de Beaumont, La Pucelle de Tonnerre: les Vicissitudes du Chevalier et de la Chevalière d'Eon
}

\author{
Maria Immacolata Spagna
}

\section{NOTIZIA}

EON DE BEAUMONT, Charles Geneviève Louis Auguste André Timothée d', La Pucelle de Tonnerre: les Vicissitudes du Chevalier et de la Chevalière d'Eon, translated and edited by Roland A. CHAMPAGNE, Nina EKSTEIN and Gary KATES, The Maiden of Tonnerre: the Vicissitudes of the Chevalier and the Chevalière d'Eon, Baltimore and London, The Johns Hopkins University Press, 2001, pp. 207.

1 Il presente volume è l'autobiografia del Cavaliere d'Eon (1728-1810), un uomo divenuto famoso non tanto per la sua intensa carriera politica e militare o per i suoi scritti di storia, finanza e politica, quanto piuttosto per aver vissuto gli ultimi trentadue anni della sua vita fingendosi una donna.

Quando d'Eon scrive le sue memorie tutti lo credono una donna, cresciuta dai genitori come un ragazzo e che ha continuato la sua vita da uomo fino a quando non decide di dichiarare la propria identità femminile.

3 Proprio per questo l'intera autobiografia deve essere letta, secondo quanto suggerisce Gary Kates, uno del traduttori e curatori di quest'edizione, come una storia complessa raccontata apparentemente da una donna che ha passato metà della sua vita come uomo, mentre in realtà dovrebbe trattarsi dell'autobiografia di un uomo che ha trascorso metà della sua vita come donna.

4 L'obiettivo, in ogni casa, che l'autore vuole raggiungere è quello di giustificare ai lettori i motivi del suo travestimento. A tal fine inventa quattro aneddoti. Il primo riguarda la sua infanzia; per legittimare il sua camuffamento fa cadere la colpa sui suoi genitori che, dopa la morte del fratello maggiore, lo hanno allevato come un ragazzo per 
alleviare il loro dolore e per sostituire in qualche modo una presenza che non c'era più. Il secondo si riferisce al primo incarico diplomatico in Russia e gli serve per mostrare il suo mascheramento come escamotage per servire la Francia, giacché la finta identità femminile gli ha permesso di divenire un, intima confidente dell'imperatrice russa Elisabetta e, di conseguenza, di prevenire Luigi XV sulle iniziative russe. Il terzo aneddoto spiega che la sua identità sessuale è stata scoperta in seguito ad una caduta da cavallo. L'ultimo aneddoto, infine, riguardante le lettere e le conversazioni scambiate con la madre, insiste sull'esortazione, da parte di quest'ultima, a non svelare la sua vera identità.

5 L'autobiografia presenta, quindi, delle storie fittizie, ma sicuramente tutte si riferiscono a personaggi realmente vissuti e conosciuti da d'Eon, posti veramente esistiti e da lui frequentati, avvenimenti effettivamente accaduti nella storia europea e di cui lui è stato testimone.

6 L'archivio di Leeds che conserva i manoscritti di d'Eon comprende diverse versioni della stessa narrativa, giacché il Cavaliere ritoma a correggere più volte i suoi saggi autobiografici. Questo volume, diviso in tre sezioni, contiene, in una prima parte, la versione più completa e raffinata dell'autobiografia di d'Eon: The Great Historical Epistle by the Chevalière d'Eon, Written in 1785, che presenta tutti i momenti importanti della vita dell'autore, compreso il processo a Londra che tendeva a stabilire se fosse uomo o donna e le varie tappe della carriera politica e militare a contatto con personaggi illustri come l'Imperatrice Elisabetta di Russia o il re Luigi XV. La seconda parte, Other Autobiographical Writings and Fragments, raccoglie alcuni frammenti delle prime versioni dell'autobiografia e di altre schede o appunti di d'Eon in una prosa più rudimentale ed un tono più naturale rispetto alla versione della prima sezione. La terza è un documento a sé, dal titolo Historical Precedents Found by d'Eon, perché presenta la storia di donne che hanno scelto di camuffare la loro identità sessuale per motivi religiosi e che sono state riconosciute sante dalla Chiesa greca e latina: Santa Eugenia, Santa Maria, Santa Teodora d'Alessandria ed altre; un documento utile a d'Eon per giustificare il suo travestimento.

7 Il punto di riferimento più ricorrente in queste pagine autobiografiche è il dogma cristiano. Egli tende a dare un significato spirituale alle metamorfosi della sua personalità che mirava a vivere come una donna cristiana interamente votata a Dio. Quest'argomento gli serviva come escamotage per mostrare il suo comportamento come una rigenerazione morale perché gli permetteva di purificarsi e di avvicinarsi a Dio.

Quest'autobiogratia ricca di sorprese costituisce un prezioso contributo per conoscere alcuni personaggi importanti del periodo in cui vive d'Eon sullo sfondo degli avvenimenti politici della seconda metà del XVIII secolo. 